holism the root is much more deep and Planned surgical admissions cancerous.

Department of Paediatrics Bury General Hospital,

1 Johnson AAW. Br Med $\mathcal{f} 1860: 41$ and 61. We $\mathrm{CH}$, Silverman $\mathrm{FN}_{2}$, Steele BF, Droegemuelle W

Child abuse. London: Fontana, 1978.

\section{Deaths from non-accidental injury in children}

SIR,-Dr H Valman states (15 March, p 775 ) that 100 children a year die from non-accidental injury. In 1973 Franklin ${ }^{1}$ made the remarkable assertion that 700 children were battered to death each year and in 1978 d'Orban $^{2}$ stated that six little children are battered to death each week. These assumptions concerning child deaths from non-accidental injury do not accord with the facts. Murder was defined by Lord Chief Justice Coke (1628) as "Where a person of sound memory and dis cretion unlawfully killeth any reasonable creature in being and under the King's peace with malice aforethought express or implied death following within a year and a day.' Since 1874 the Births and Deaths Registration Act has required all deaths in the United Kingdom to be medically certified and registered. Unlawful killings are reported to the coroner. Each year the Registrar Genera publishes his annual statistical survey, ${ }^{3}$ from which we learn that during the present century "deaths due to homicide and injury purposely inflicted by other persons on children under five years" have progressively declined.

In 1900 the number of such deaths was 87 In 1910 it had risen to 115 (the maximum ever). Since 1915 the number of these deaths has steadily decreased. Last year the total number had fallen to $78 .^{4}$ The total population of England and Wales during this period has increased from 19 million to 49 million. The percentage infantile homicidal deaths compared with the total population was in 1874 0.00056 and in 19790.00016 .

Will Dr Valman tell us where 22 babies were buried without the coroner, the police, or the registrar general being told?

KENNETH T FARN

Atherstone, Warwicks CV9 2PE

1 White Franklin A (compiler) Nam-accidental injuries to children: Tunbridge Wells Study Group report. Meeting sponsored by Medical Education a Information Unit of the Spastic Society, 1973.

d'Orban P. British Medicine. 15 August 1978:9.

Central Statistical Office. Annual abstracts of statistics. London: HMSO, 1880 et seq

Office of Population Censuses and Surveys. Mortality

statistics: childho

** We sent a copy of this letter to Dr Valman, whose reply is printed below.-ED, BMF.

SIR,-Dr Farn notes that 78 infants die as a result of inflicted injury but we rounded the figure to 100 . The object of quoting an incidence was to contrast the number of cot deaths (2000 a year) with deaths from inflicted injury. This shows that if an infant is found dead unexpectedly the chance that the death is due to natural causes is about 20 to 1 .

H B VALMAN
SIR,-I am interested to see the article on planned surgical admissions by $\mathrm{Mr} \mathrm{J} A$ Southam and $\mathrm{Mr} \mathrm{R}$ W Talbot (15 March p 808). I believe that the method they describe is more widely used than they may suspect.

I first learnt to use a unit diary for surgical admissions when I succeeded $\mathrm{Mr}$ Ivor Lewis at North Middlesex Hospital in 1952. I have practised this method at St Albans Hospital ever since, though I was using a very simila method before then. Only later was I able to get the diary method introduced for my patients at the Royal Northern Hospital by the en thusiasm of a former senior registrar, $\mathrm{Mr}$ John Dormandy.

The scheme has always been easier to administer at St Albans, where I have my unit secretary in an office alongside the consulting room. Patients for operation are appropriately entered in the diary and generally given their date for admission at the time of consultation which obviates the need in most cases for a subsequent letter. Moreover, to avoid any last-minute problems over availability of beds for less serious cases, we generally get such patients to telephone the ward on the morning of admission lest unforseen problems should have arisen as a result of excessive emergency admissions.

The majority of my trainees, who are now consultants, tell me that they use the sam basic methods in their own hospitals. The system is not only far better for the surgical team and for the patients; it also makes planned surgical training much easier and ensures that the unit secretary is an essential feature of the hospital economy in a much more fulfilling job. I commend the system to any who may not have already used it, though I recognise that it is more difficult to implement in some places.

ReginALD MURLEY

Royal College of Surgeons of England,

London WC2A 3PN

\section{Antibiotics in appendicectomy}

SIR, - We wish to reply to comments made by Mr Douglas Stewart and others (15 March, $p$ 794) on our paper on the use of antibiotics after appendicectomy (2 February, p 275). We accept his point that the wound infection rate in patients with only gangrenous appendice was acceptable at $4.5 \%$. The busy young surgeon, who normally treats appendicitis, will readily differentiate between an inflamed appendix and one that is gangrenous, perforated, or both, but he is less likely to want to separate gangrenous from perforated appendixes, where the distinction is less clear. This was the impression we obtained from our junior colleagues during the trial, although they complied fully with the protocol requirements. Hence the recommendation for cephazolin and metronidazole together in this combined group. Mr Stewart mentions the importance of intraoperative antibiotic peritoneal and wound lavage; we are aware of this study but were no concerned to test these procedures as part of an investigation into systemic antibiotic regimens.

Mr A Kingsnorth (p 794) states that ampicil lin, by being given intramuscularly as soon as the condition of the appendix was diagnosed was disadvantaged in comparison with metro nidazole given by suppository one hour before operation. Ampicillin, however, would pene- trate the operation site well within the first postoperative hour and therefore would be active within the time limit set by the work of Burke. ${ }^{1}$ In an attempt to reduce the septic complication rate we recommended cephazolin because of the poor performance of ampicillin in our trial and in view of our own good clinical experience with it. A multicentre study comparing metronidazole with metronidazole and cephazolin has been instituted.

Mr M J Kelly (p 794) will have noted that we used suppositories of metronidazole throughout our trial and that the recommendation for intravenous metronidazole fulfils the need to supply the drug rapidly after diagnosis of the state of the appendix. We recommended a certain dosage postoperatively but not that it must be given intravenously; indeed, after the first intravenous dose we give the drug by suppository until the patient can take it by mouth.

P J SANDERSON DOMINIC PINTO

Northwick Park Hospital,

${ }^{1}$ Burke JF. Surgery 1961; 50-161-8.

\section{Sepsis after bowel surgery}

SIR,-I enjoyed your leading article "Sepsis after bowel surgery" (29 March, p 882). I was glad that it stressed the importance of surgical technique in the prevention of sepsis in colorectal surgery. I was surprised therefore to discover no mention of the circular stapling device now used by many intestinal surgeons for low anterior resection. There is no doubt that the use of this instrument has reduced the risk of anastomotic dehiscence, which the authors rightly point out is a most important cause of secondary infection. In our own unit our overall sepsis rate remains less than $10 \%$ when metronidazole and the end-to-end anastomosis stapling device have been used for rectal cancer.

One important dilemma remains: namely, whether or not the addition of an aminoglycoside is in fact necessary when metronidazole is used. Eykyn and her colleagues ${ }^{1}$ showed that metronidazole alone had a dramatic effect on postoperative sepsis even when the incidence of anastomotic dehiscence was quite high. We believe there is an urgent need for a trial to determine whether metronidazole alone is as effective as metronidazole in combination with either an aminoglycoside or a cephalosporin.

M R B KEIGHLEY

University Department of Surgery,

The General Hospital,

1 Eykyn SJ, Jackson BT, Lockhart-Mummery HE, Phillips I. Lancet 1970;ii:761-4.

\section{Setting up a drip}

SIR,-We were interested to read the article on setting up an intravenous drip (16 February, p 463) by Drs Barbara Bannister and C W H Harvard, together with the subsequent letters by Drs $M$ Jolles, J Hart, and W $G$ Notcutt (22 March, p 865). We also feel that more care and attention should be exercised in the selection and performance of these procedures. Poor aseptic and surgical technique may result in unnecessary pain for the patient from thrombophlebitis, subcutaneous infusion of fluids, or even skin necrosis. We should like to 
endorse their advice to junior staff concerning the careful preparation of the vein and the use of local anaesthesia.

Dr Notcutt has emphasised that the use of paper tape does little to support an intravenous cannula after insertion. An additional point against the use of this technique is that the placement of such "chevrons" of tape around the shaft or hub of the cannula, adjacent to the skin puncture site, immediately contaminates the device, so carefully sterilised by the manufacturer. At the present time we are conducting a pilot study on general surgical patients to evaluate a new intravenous cannula Op-Site dressing (Smith and Nephew UK, $6 \times 8.5 \mathrm{~cm}$ ). Our initial findings have shown excellent fixation of the cannulas; no thrombophlebitis has been evident on clinical inspection and there has been no subcutaneous extravasation of infused fluid to date ( 60 dressings, Wallace UK cannulas; average cannula placement time 2.6 days). Ths skin puncture site can easily be inspected for complications. The dressing is best applied to dry, shaved, and prepared skin. The application of the dressing is easily performed by a non-touch sterile technique. When the dressing is in place the skin puncture site and the exposed shaft of the cannula up to but not including the hub are covered. This effectively prevents contamination and unwanted movement of the cannula. The need for any extra bandages has been almost eliminated. The dressing is also ideal for securing "butterfly" cannulas during anaesthesia.

In our opinion, this will be of significan benefit for patient care by encouraging the adoption of meticulous technique and aiding the nursing profession in the maintenance of sterile intravenous infusion sites.

Joseph L PETERS DAPHNE J GRIFFITH

C A HACKWORTHY $S$ WATT-SMITH

University College Hospital,

SIR,-The comments made by Drs Dermot Phelan and Myles MacEvilly (29 March, p 942) on the article by Drs Barbara Banniste and C W H Havard (16 February, p 643) include the recommendation that intramuscular morphine sulphate $0.1 \mathrm{mg} / \mathrm{kg}$ should be given to distressed children before siting an intravenous line.

It has been the experience of this unit that the distress caused by such a procedure can in most cases be alleviated by firm restraint, reassurance, and good nursing technique- on occasion supplemented by light sedation (for example, trimeprazine). In no instance, from our combined cases, has it been necessary to resort to sedation and analgesia with opiates before intravenous therapy is started in children.

Paediatric Unit,

Carshalton, Surrey SM5 1AA

John B Aspinal

\section{Desmopressin (DDAVP) in lumbar puncture}

SIR,-Dr J M A Cowan and others (26 January, p 224) have reported a double-blind controlled study of intramuscularly administrated desmopressin (1-desamino-8-arginine vasopressin, DDAVP) to fifty patients who had had a diagnostic lumbar puncture. They conclude that DDAVP does not affect the incidence of headache after lumbar puncture, but lessens the disability. They therefore recommend a trial of intranasally administere DDAVP for established headache after lumbar puncture.

Firstly, we do not consider it feasible to apply the Fisher exact test as it has been applied in this study, because the data used do not fall into one or the other of two mutually exclusive classes. The scores represent the most significant looking differences in a large contingency table than is shown in the article (see accompanying table). Testing by combining the last two columns in the table and

Headache after lumbar puncture in patients taking DDAVP and placebo (Cowan et al)

\begin{tabular}{lcccc}
\hline & $\begin{array}{c}\text { No of } \\
\text { headache-free } \\
\text { periods }\end{array}$ & \multicolumn{3}{c}{ No of headache periods } \\
\cline { 3 - 5 } Drug & Mild & Moderate & Severe \\
\hline $\begin{array}{l}\text { DDAVP } \\
\text { Placebo }\end{array}$ & 88 & 9 & 3 & 0 \\
& 87 & 5 & 2 & 6
\end{tabular}

applying the $\chi^{2}$ test we find $p\left(\chi^{2}\right)=0 \cdot 82$, which means $p=0 \cdot 18$. Application of the MannWhitney $U$ test to the table as it stands yield $p=0.44$. The $p$ values (two- or one-tailed tests) are not significant at the usual 5\% level. Thus applying the Fisher test to differences inside the table distorts the significance level gravely. It is therefore preferable to accept the differences as due to chance. From this point of view there is no reason to conclude from the actual study that disability after lumbar puncture is significantly lessened by DDAVP prophylaxis.

In a double-blind controlled trial we ${ }^{1}$ have investigated the possible prophylactic effect of intranasally applied DDAVP (100 $\mu \mathrm{g}$ twice a day) on the incidence of headache following lumbar puncture in 51 patients and following pneumoencephalography in 28 patients. DDAVP had no significant effect compared with placebo on the incidence of headache or on the consumption of analgesics (minimal relevant difference $=50 \%, 2 \alpha=0.05, \beta=0.50$ )

Therefore we do not think that further trials of DDAVP as a prophylactic or therapeutic remedy against headache after lumbar puncture could be rewarding.

Per Evald Hansen JOHN HERSTED HANSEN

University Department of Neurology,

Aarhus Kommunehospital, Aarhus, Denmark

Hansen PE, Hansen JH. Acta Neurol Scand 1979;60: 183-8.

\section{Cerebral atrophy or hydrocephalus?}

SIR,-The clinical dilemma posed by the title of your leading article "Cerebral atrophy or hydrocephalus ?" (9 February, p 348) is very real as surgical interference can only aggravate the progression of Alzheimer's disease. Usually the clinical diagnosis of Alzheimer's disease becomes clearer and clearer as the disease progresses steadily-slowly in most, rapidly in a few.

By contrast, the symptoms and signs of adult hydrocephalus often fluctuate in severity: the clinical picture is usually bizarre, and the classical triad of dementia, apraxia of gait, and incontinence tends to appear only at a late stage. Personal cases included one patient with late-onset epilepsy mimicking an astrocytoma and a woman with intermittent psychiatric symptoms in whom further investigations were prompted by a highly abnormal "routine" electroencephalogram (more often than not the EEG is normal in hydrocephalus). A history of predisposing factors such as trauma or brain surgery, meningitis, and subarachnoid haemorrhage is in favour of hydrocephalus.

In a personal series of 16 cases of hydrocephalus referred for surgery there were nine patients with such predisposing conditions. The five patients with idiopathic hydrocephalus were aged over 60 except for one woman aged 46. One patient was too old and one eventually proved to have irreversible neurological disease, and these two should not have been referred for surgery.

The disproportion of ventricular enlargement over cortical atrophy in computed tomography is the strongest pointer towards a diagnosis of hydrocephalus. ${ }^{1}$ Additional investigations such as isotope encephalography and pressure monitoring may be helpful; but in our cases both methods have proved misleading, either way, on occasion.

An additional pointer towards hydrocephalus is a favourable response to withdrawal of cerebrospinal fluid by lumbar puncture: Miller Fisher ${ }^{2}$ has suggested that such a good response should be immediate, but it may be delayed. Fortnightly lumbar punctures kept one patient "normal" during a 15-month period between the removal of an infected shunt and the insertion of a second successful shunt.

A combination of all these observations and methods allows a fairly confident selection of cases for shunting. Unfortunately the subsequent complication and failure rate is highfrom blockage of the shunt, infection, or the development of subdural haematomas. Even so, the success rate of $26-66 \%$ reported in the literature ${ }^{3}$ and our own favourable response in 10 out of 16 patients is as good as any in the practice of neurosurgery in general. It is not clear whether you advocate a three-year period of "blind" surgery (without knowledge of radiological data) or three years of a controlled trial of surgery versus inaction.

E H JELLINER

Northern General Hospital,

Edinburgh EH5 2DQ

$$
\begin{aligned}
& \text { Gunasekera L, Richardson AE. Brain 1977;100:749- } \\
& 54 . \\
& \text { Miller Fisher C. Lancet 1978;i:37. } \\
& \text { Greenberg JO, Shenkin HA, Adam R. F Neurol } \\
& \text { Neurosurg Psychiatry 1977;40:336-41. }
\end{aligned}
$$

** To establish the place of certain methods of radiological investigation (for example, isotope cisternography and computed tomography with metrizamide) we suggested that the results of these investigations should be withheld from the clinicians until adequate time had elapsed for follow-up of a sufficient number of patients. Jellinek's comments are helpful and most clinicians would agree with his clinical criteria for shunting; an essential part of the suggested study would be that the clinicians' criteria for shunting, based on the clinical findings and the results of static computed tomography, would continue to be used. Not all centres have ready access to prolonged intracranial pressure monitoring and so we must still attempt to define precisely the place of other methods of investigation.ED, BMF. 